\title{
Transapical aortic valve implantation in humans
}

\author{
Jian Ye, MD, Anson Cheung, MD, Samuel V. Lichtenstein, MD, PhD, Ronald G. Carere, MD, \\ Christopher R. Thompson, MD, Sanjeewan Pasupati, MD, and John G. Webb, MD, Vancouver, BC, Canada
}

\section{See related editorial on page 941.}

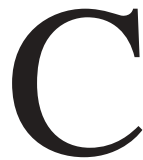

alcific aortic stenosis is the most common valvular disease affecting the elderly. Surgical aortic valve replacement improves symptoms and prognosis, but mortalities may be as high as $20 \%$ in elderly patients with left ventricular dysfunction. ${ }^{1}$ Catheter-based aortic valve implantation was recently achieved through antegrade venous ${ }^{2}$ and retrograde arterial routes. ${ }^{3}$ We report on the deployment of an aortic valve prosthesis for severe aortic stenosis through the apex of the left ventricle in a 75-year-old patient without cardiopulmonary bypass or sternotomy.

\section{Methods}

\section{Case Report}

The procedure was approved by the Therapeutic Products Directorate, Department of Health and Welfare, Ottawa, Canada, for compassionate clinical use in patients deemed not to be candidates for surgery and without arterial access.

An emaciated, 52-kg, 75-year-old woman presented in congestive heart failure. Comorbidities included restrictive lung disease, severe psoriatic arthropathy, a calcified thoracic aorta, a large infrarenal aortic aneurysm, and bilateral aortoiliac disease. Cardiac catheterization revealed pulmonary hypertension and severe aortic stenosis with a mean gradient of $54 \mathrm{~mm} \mathrm{Hg}$ and $0.4 \mathrm{~cm}^{2}$ valve area. Echocardiograms demonstrated a mean gradient of 31 to 48 $\mathrm{mm} \mathrm{Hg}, 0.7$ to $0.8 \mathrm{~cm}^{2}$ valve area, $23-\mathrm{mm}$ ventriculo-annular diameter, and ejection fraction of $35 \%$ (Figure 1, A).

The patient was evaluated by 2 surgeons who believed the operative risk was unacceptable, and she was referred for consideration of transapical deployment of an aortic valve prosthesis.

\section{Procedure and Results}

The procedure took place in the operating room under general anesthesia on October 27, 2005. A portable C-arm provided

From the Divisions of Cardiac Surgery and Cardiology, St Paul's Hospital, University of British Columbia, Vancouver, BC, Canada.

Dr John Webb is a consultant at Edwards Lifesciences, Irvine, Calif.

Received for publication Nov 28, 2005; revisions received Jan 04, 2006; accepted for publication Jan 12, 2006.

Address for reprints: Samuel V. Lichtenstein, MD, PhD, Head, Cardiac Surgery, University of British Columbia, 1081 Burrard Street, Vancouver, BC, Canada V6Z 1Y6 (E-mail: slichtenstein@ providencehealth.bc.ca).

J Thorac Cardiovasc Surg 2006;131:1194-6

$0022-5223 / \$ 32.00$

Copyright @ 2006 by The American Association for Thoracic Surgery doi:10.1016/j.jtcvs.2006.01.026 fluoroscopy. Aortography, through a right femoral arterial sheath, and transesophageal echocardiography were used to facilitate positioning of the prosthesis. The patient was premedicated with $300 \mathrm{mg}$ clopidogrel, $81 \mathrm{mg}$ aspirin, and vancomycin $1 \mathrm{~g}$ intravenously.

The pleural space was entered through a 5-to-8-cm sixth intercostal anterolateral thoracotomy. The pericardium over the apex of the left ventricle was identified and opened. To permit a $24 \mathrm{~F}$ sheath, 2 paired orthogonal U-shaped sutures with pledgets were placed into the myocardium and passed through tensioning tourniquets. Temporary epicardial pacing wires were placed. Test pacing was performed to ensure reliable 1:1 capture at 150 to 200 beats/min and reduction in arterial pressure to less than $50 \mathrm{~mm} \mathrm{Hg}$. During valvuloplasty and prosthesis deployment, rapid pacing was used to minimize transaortic flow.

After 5000 units of heparin were administered, an 8F Angiocath was inserted through the apex of the left ventricle and a guidewire was passed through the aortic valve and down the descending aorta for stability. The Angiocath was exchanged for a $14 \mathrm{~F}$ catheter, and a $20-\mathrm{mm}$ balloon valvuloplasty was performed in preparation for valve deployment.

The Cribier valve (Edwards Lifesciences Inc, Irvine, Calif) is a 26-mm stainless-steel stent with an attached equine pericardial trileaflet valve and an annular fabric cuff. The valve was supplied sterile in glutaraldehyde and required onsite mechanical crimping onto a valvuloplasty balloon. A stiff $24 \mathrm{~F}$ valve delivery sheath was introduced into the left ventricle and consciously kept in line with the aortic valve. The collapsed prosthetic valve was positioned by aortic root angiography (Figure 2, A) and echocardiography.

A coordinated approach was developed. One individual observed the fluoroscopic image and maintained ideal valve position. A second individual initiated pacing. A third individual confirmed pacemaker capture and reduction in arterial pressure before rapidly inflating and deflating the stent deployment balloon.

Echocardiography reported a resultant valve area of $1.9 \mathrm{~cm}^{2}$ with a $3 \mathrm{~mm} \mathrm{Hg}$ gradient (Figure 1, B). Aortic root angiography confirmed appropriate placement with no regurgitation (Figure 2, B).

Hemostasis was secured with previously placed pledgeted sutures. The pericardium was reapproximated to allow drainage and prevent myocardial herniation. A left chest tube drained $200 \mathrm{~mL}$ of serosanguineous fluid.

The patient was well and able to walk 3 days postprocedure without neurologic defects or shortness of breath. Repeat echocardiogram demonstrated a well-seated, normally functioning prosthesis without regurgitation. She was placed on $75 \mathrm{mg}$ clopidogrel for 2 months and $81 \mathrm{mg}$ aspirin daily. Because she lives alone, she was discharged 9 days postprocedure.

The 1-month postoperative echocardiogram demonstrated a valve area of $1.7 \mathrm{~cm}^{2}$ with minimal paravalvular insufficiency. At approximately 2 months follow-up she remains in sinus rhythm, 

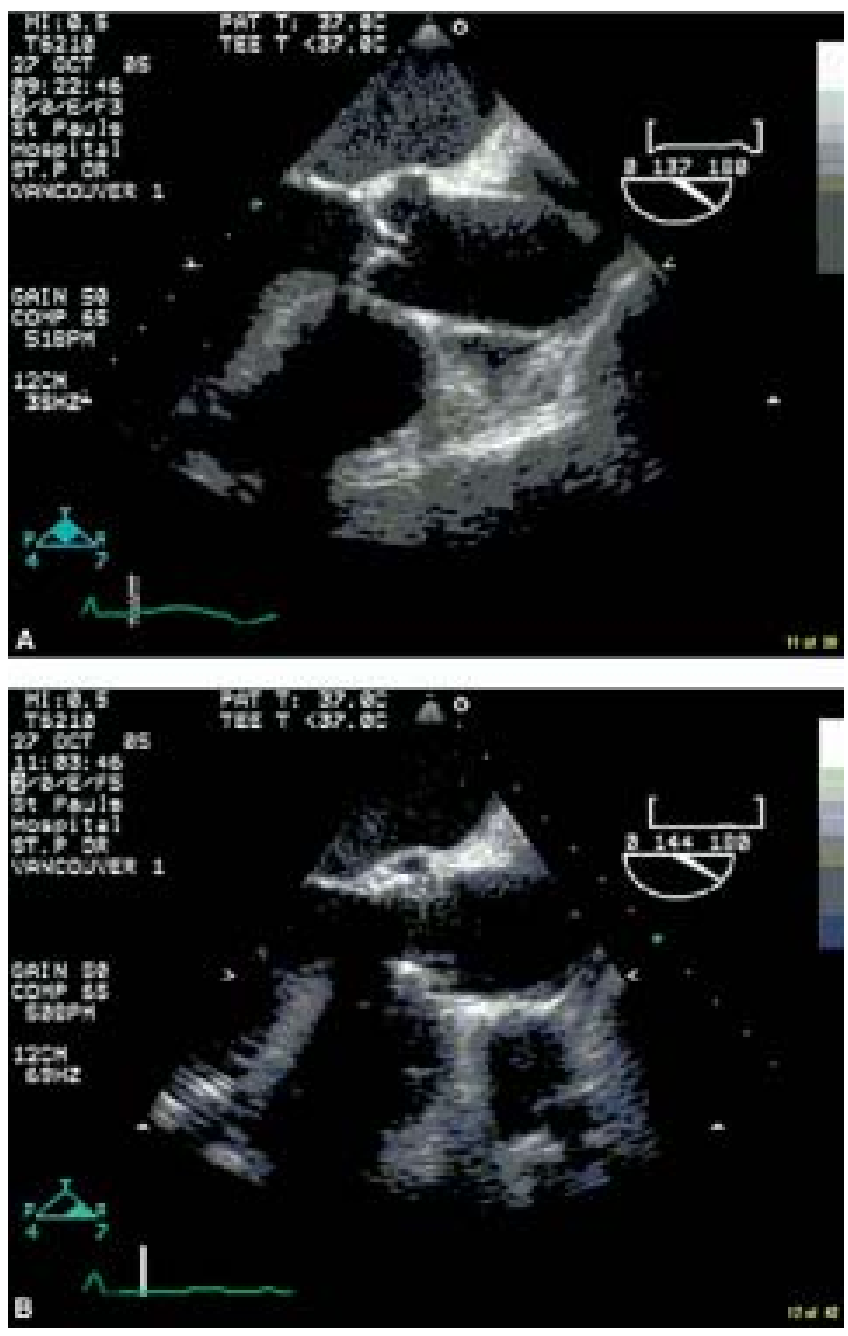

Figure 1. Transesophageal echocardiogram. Transesophageal echocardiogram (preoperative and postoperative long access). A, Long access-preoperative. Maximum opening of the thickened leaflets is severely restricted. Restrictive calcium can be visualized at the annulus and on the leaflets. B, Long access-postoperative. Stent valve is well positioned with unrestricted leaflet opening.

free of complications, and without any heart failure, functionally limited only by preexisting arthropathy.

\section{Discussion}

This case demonstrates the successful implantation of an aortic valve prosthesis for aortic stenosis through the apex of the left ventricle without sternotomy or the use of cardiopulmonary bypass in a human. The resultant hemodynamics and valve area are compatible with those achievable with open surgical replacement.

At present this procedure is offered to symptomatic patients deemed to be nonsurgical candidates without peripheral arterial access. With technologic advances, improved techniques, better understood selection criteria, and prosthesis durability, the indications may be expanded to high-risk surgical candidates.
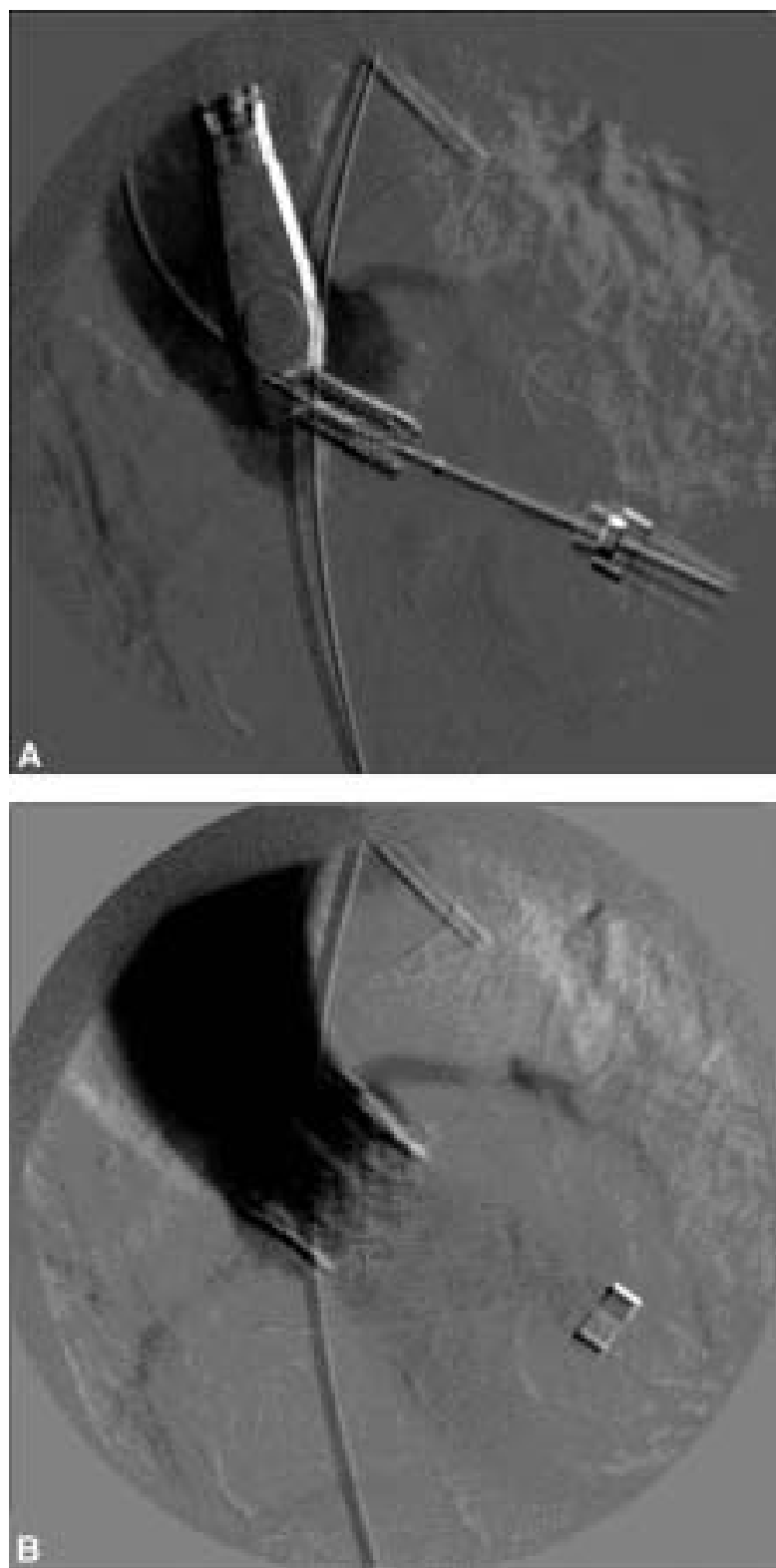

Figure 2. Ascending aortograms. Ascending aortograms (positioning of valve prosthesis before implantation and after prosthetic valve implantation). A, Positioning of valve prosthesis before implantation. A, Transesophageal echocardiogram probe to help with positioning at the aortic annulus and apical left ventricular deployment catheter and sheath. B , After prosthetic valve implantation. $B$, Prosthesis is positioned at the annulus and below the coronary ostia. There is no aortic insufficiency.

This case demonstrates the feasibility of this approach and portends an evolving future for transchamber treatment of intracardiac pathology by cardiac surgeons.

We thank Dr Todd Dewey for his advice and guidance in this case. 


\section{References}

1. Alexander K, Ansstrom K, Muhlbaier LH, Grosswald RD, Smith PK, Jones RH, et al. Outcomes of cardiac surgery in patients age $>80$ years: results from the National Cardiovascular network. J Am Coll Cardiol. 2000;35:731-8.
2. Cribier A, Etchaninoff H, Bash A, Borrenstein N, Tron C, Bauer F, et al. Percutaneous trans-catheter implantation of an aortic valve prosthesis for calcific aortic stenosis; first human case description. Circulation. 2002;106:3006-8.

3. Webb JG, Chandavimol M, Ricci DR, Carere RG, Thompson CR, Munt $\mathrm{BI}$, et al. Percutaneous aortic valve implantation retrograde from the femoral artery. Circulation. 2006;113:842-50.

\title{
Nourishing vascularization of a thymoma issued from a left internal thoracic artery graft
}

\author{
Pascal A. Thomas, MD, Frédéric Collart, MD, Christophe Doddoli, MD, Vlad Gariboldi, MD,
} and Guy Moulin, MD, Marseille, France

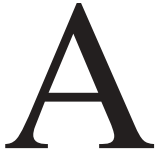

71-year-old man underwent chest computed tomographic (CT) scan in June 2002 as part of an ongoing program for thoracic malignancy screening because he was a former worker with significant exposure to asbestos. In 1988, he had received one left internal thoracic artery (LITA) graft to the mid left anterior descending artery and one saphenous vein graft to the first marginal branch of the left circumflex artery because of severe angina. The chest CT scan identified a $5-\mathrm{cm}$ homogeneous anterior mediastinal mass located on the left aspect of the thymic area (Figure 1). The LITA graft was shown as contiguous with the tumor. Selective catheterization of the LITA disclosed a patent graft as well as a rich, nourishing vasculature supplying the tumor and originating from the graft (Figure 2). Coronary arteriography revealed severe native vessel disease with complete occlusion of the right and $70 \%$ obstruction of the distal left main coronary arteries. Left ventriculography showed no wall motion abnormalities and an ejection fraction of $60 \%$. The patient underwent percutaneous transluminal left main coronary angioplasty with stent placement on July 2002, followed by a 60-day course of clopidogrel with aspirin, subsequently relieved with daily subcutaneous injections of enoxaparin. In October 2002, the patient was operated on through a left lateral thoracotomy. The tumor was adherent to the pericardium and the LITA graft. It was carefully freed from the graft with elective control of all collateral microvessels by bipolar electrocoagulation forceps, division of the thymic veins draining into the innominate vein, and establishment of the

From the Departments of Thoracic Surgery, Cardiac Surgery, and Radiology, Sainte Marguerite \& La Timone University Hospitals, Marseille, France.

Received for publication Nov 22, 2005; accepted for publication Dec 16, 2005.

Address for reprints: P. Thomas, MD, Department of Thoracic Surgery, Ste Marguerite Hospital_CHU Sud, 270 Bd Ste Marguerite, 13274 Marseille Cedex 9, France (E-mail: Pascal-alexandre.Thomas@mail.ap-hm.fr).

J Thorac Cardiovasc Surg 2006;131:1196-7

$0022-5223 / \$ 32.00$

Copyright $\odot 2006$ by The American Association for Thoracic Surgery doi:10.1016/j.jtcvs.2005.12.031

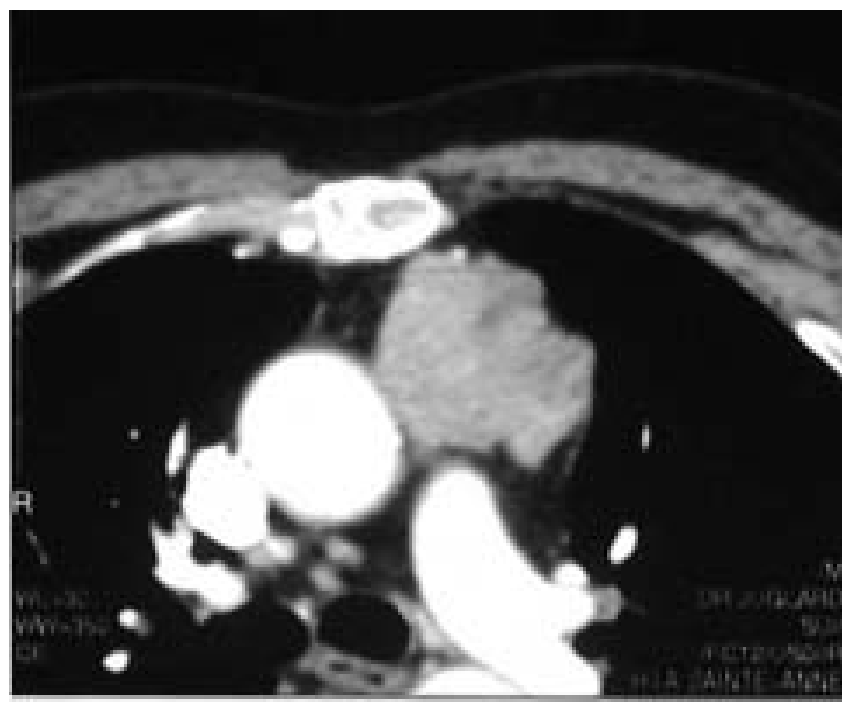

Figure 1. CT scan of the chest showing an anterior mediastinal mass and the LITA graft as an adjacent contrast-enhanced vessel along its anterior aspect.

lateral margin of resection just anterior to the left phrenic nerve. The patient made an uneventful recovery and was discharged on day 11.

Pathologic examination revealed a mixed thymoma according to the Müller-Hermelink classification, with focal invasion of the capsule. The patient was given adjuvant radiotherapy to the mediastinum (50 Gy in 25 fractions). He remains free from recurrence and angina 3 years after the operation.

\section{Discussion}

Surgery remains the standard of care for encapsulated thymomas, with high cure rates anticipated. Thymomas are the most common thymic tumor in adults, usually with an indolent growth pattern. Understandably, the fortuitous discovery of a thymoma during a 